Rev. IG, São Paulo, 1(2):33-38, jul./dez. 1980

\title{
CONTRIBUIÇÃO DA MORFOLOGIA DOS FÓSSEIS PARA DEDUÇÃO DE PALEOAMBIENTES
}

\author{
Geólogo PERCY CORREA VIEIRA - Pesquisador Científico
}

\section{RESUMO}

O restos fossilizados dos seres que viveram antes da época atual podem servir para deduções dos ambientes em que esses seres viveram.

Estando os organismos adaptados ao modo de vida, deduz-se serem de particular importância as formas anatômicas derivadas dessas adaptações.

As formas adaptativas não se transmitem à descendência quando espelham caracteres adquiridos e nesse caso tornam-se particularmente importantes na dedução paleoambiental.

\begin{abstract}
This paper presents the relationships between the fossil morphology and the paleo-environment. This work is based on a branch of Paleoecology which studies the fossils adaptation in the environment.

As the organisms are adjusted to the environment we conclude that is very important the anatomic shapes proceeded from this adaptation.
\end{abstract}

\section{INTRODUÇÃO}

Este trabalho é um resumo da palestra proferida no Instituto Geológico, no ano de 1980 , em comemoração à "Semana do Meio Ambiente".

A encrme carência de publicações científicas nacionais na utilização da morfologia dos fósseis para dedução paleoambiental, em contraste com a abundância estrangeira, moveu-nos a publicar esta matéria.

Nosso objetivo é o de estabelecer conceitos e acentuar os cuidados e caminhos que devem ser seguidos por quem intente fazer pesquisa paleoambiental com base na composição morfológica dos fósseis.

Os itens não foram dcsenvolvidos em suas partes mínimas e mesmo as definições estão postas sem as necessárias complementações, já que nosso intuito é simplesmente o de chamar a atenção dos leitores para este "novel assunto" e quiçá despertar aptidões.

\section{CONCEITOS DE AMBIENTE \\ E PALEOAMBIENTE}

Ambiente é o meio em que se está, é o que está à roda ou envolve alguma coisa. Para o propósito deste trabalho, ambiente é o meio natural (físico, químico e orgânico).

Paleoambiente é um ambiente do passado geológico, o qual normalmente não persiste até hoje.

Os fatores naturais mais influentes na constituição de um ambiente são: temperatura, pressão (atmosférica ou hidrostática), profundidade da água, altitude, composição atmosférica e da água, luminosidade, umidade, salinidade, correnteza da água ou do ar, abundância de matéria orgânica, existência de seres vivos e suas relações, etc., bem como fatores geológicos e geográficos tais como: campo gravitacional e magnético, sonoridade, latitude e longitude, sismicidade, vulcanismo, sedimentação, orogenia e outros. $\bar{A}$ interação 
de alguns desses fatores numa particular região dá-se o nome de "habitat".

Mais aprofundadamente poderíamos dizer que os meios de vida compõem-se de fatores abióticos, que são inorgânicos (físicos e químicos) e bióticos, que são orgânicos (biológicos). É de sua interação que surge o meio total.

\section{CLASSIFICAÇÃO DOS AMBIENTES}

Os ambientes (e também os paleombientes, em virtude do princípio do atualismo) podem ser divididos ecologicamente em continentais e marinhos, que por sua vez podem ser subdivididos conforme o seguinte quadro (ROCHA CAMPOS, inf. verbal):

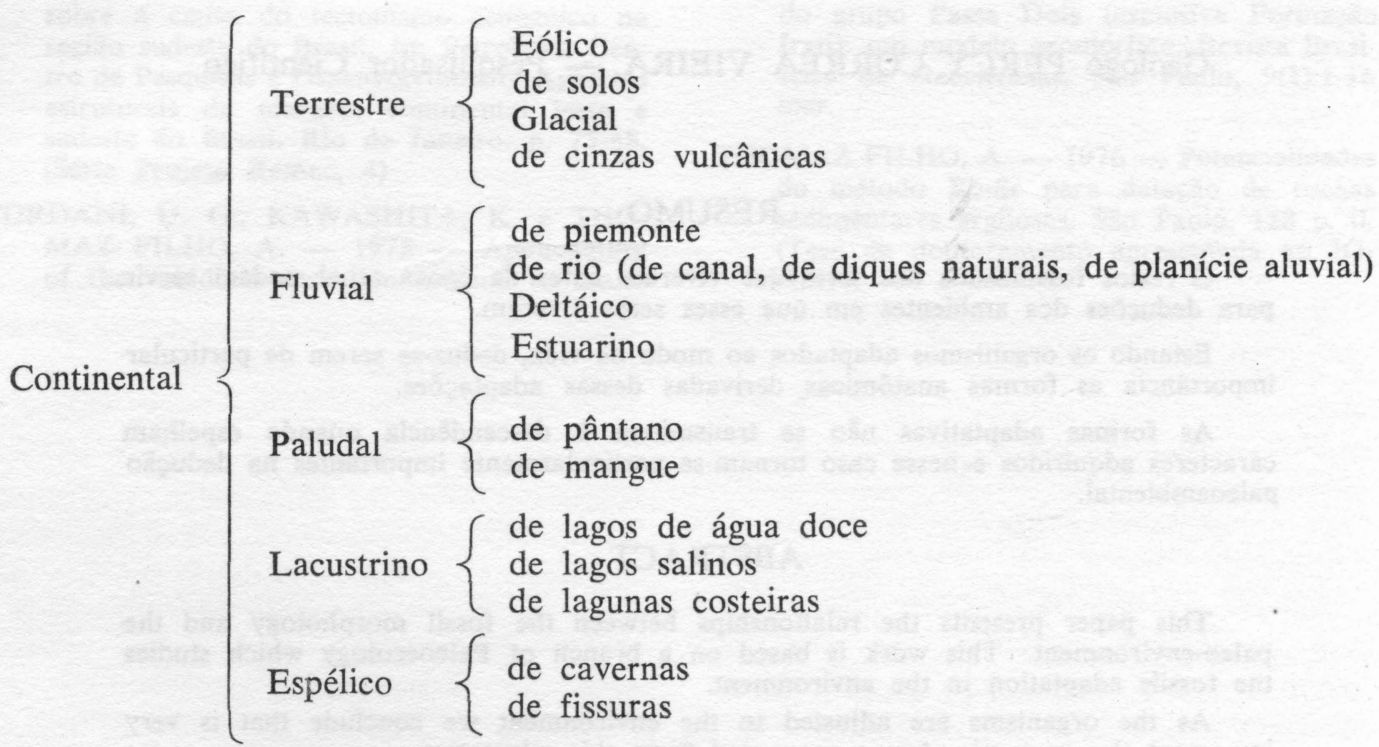

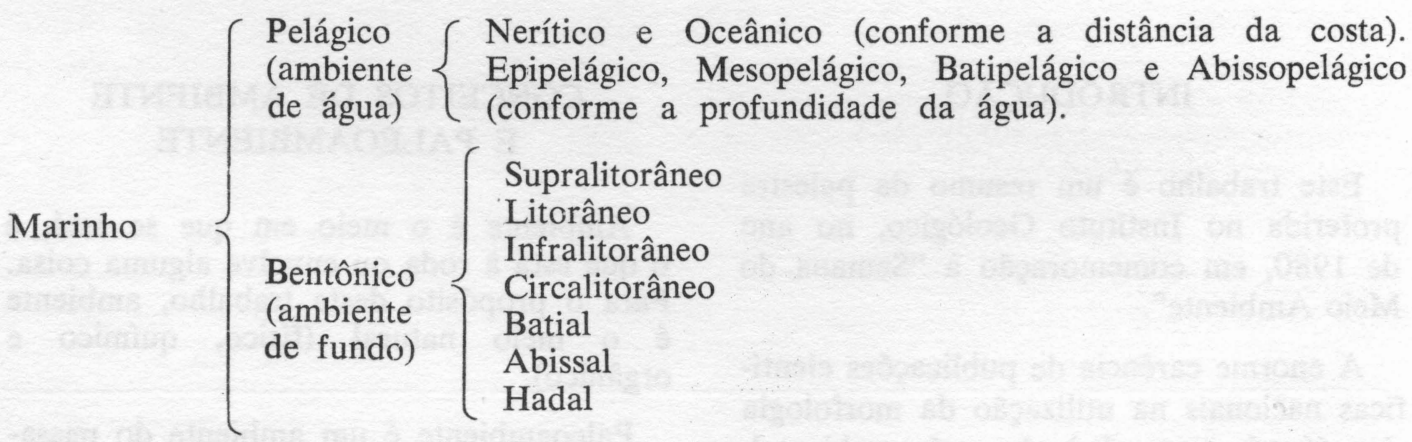

RELAÇÕES ENTRE

PALEOECOLOGIA, BIOLOGIA, PALEONTOLOGIA E GEOLOGIA

A Biologia estuda os seres vivos no momento presente enquanto que a Paleontologia estuda os seres que viveram antes da época atual e que são conhecidos através de seus, restos ou vestígios. A Ecologia tem por objeto estudar as interrelações entre os organismos atuais e seu ambiente, enquanto que a Paleoecologia estuda as interrelações entre os seres fósseis e seus ambientes de vida.
A Paleoecologia sofre três limitações em relação à Ecologia, que são: $1 .^{\mathrm{a}}$ Os organismos viventes, agora preservados como fósseis não podem ser observados como um todo, já que normalmente só as partes duras mantêm-se; $2 .^{\mathrm{a}}$ —os atributos físicos e químicos de antigos ambientes geralmente não podem ser reconstituídos; $3 .^{\mathrm{a}}$ - o registro fóssil é grandemente influenciado pelos processos "post mortem" e pós-deposicionais.

Talvez o mais excitante aspecto da Paleoecologia em relação à Paleontologia seja a evolução, já que a doutrina da 
sobrevivência do mais adaptado é basica. mente matéria ecológica, desde que os mais adaptados a sobreviver são os melhores adaptados em termos de hábito e "habitat". Infelizmente a grande maioria dos estudos evolucionários em Paleontologia tem sido feita em simples base de sucessão morfológica desligada do estudo de ambientes contemporâneos e sucessivos.

A Paleoecologia relaciona-se à Geologia no sentido de que os antigos ambientes, via de regra, ficaram representados nas rochas. Deste modo sabe-se que os sedimentos podem fornecer dados sobre os ambientes nos quais antigos organismos viveram. Sob este aspecto parece-nos também importante enfatizar que as correlações estratigráficas feitas sem levar em consideração paleoambientes, muitas vezes têm induzido o pesquisador a incorrer $\mathrm{em}$ erro.

Ecossistema é o interrelacionamento entre o biota $e$, seu ambiente físico, paleoecossistema é o mesmo, agora considerando os paleoambientes. $\mathrm{O}$ paleoecossistema vê-se grandemente influenciado pelas mudanças pós-deposicionais, de natureza diagenética. Assim a diagênese, junto ccm o paleobiota e o paleoambiente físico atuam no desenvolvimento da facies da rocha (biofáceis e litofáceis).

\section{BASES E DIVISÕES DA PALEOECOLOGIA}

Esta ciência, como as demais ciências naturais, baseia-se em alguns princípios, que são:

$\left.1 .^{\circ}\right)$ Existe uniformitarismo de processos físicos, químicos e biológicos no tempo geológico (Atualismo).

$\left.2 .^{\circ}\right)$ Os organismos estão adaptados aos seus ambientes de vida.

$\left.3 .^{\circ}\right)$ Os organismos estão adaptados ao modo (hábito) de vida, o que produz características morfológicas distintas e estas características permitem determinar os modos de vida.

4. ${ }^{\circ}$ O ambiente e o modo de vida particular impõem limitações ecológicas. Cada organismo está adaptado a um conjunto de fatores ambientais; se faltar um, o organismo entra em desequilíbrio. As limitações ecológicas dependem tambénı da teia alimentar constituída por outros organismos.
Pode-se aqui enunciar a "Lei do mínimo", que diz: "O fator determinante na distribuição de uma espécie é o fator que existir em quantidade mínima". Assim, abaixo dessa quantidade a espécie não sobrexiste.

5.) Existem limitações de evidências fossilíferas:

a) Os restos orgânicos podem ser removidos após a morte por necrófagos, saprófitas e decomposição bacteriana; b) as partes restantes podem ou não fossilizar-se; c) havendo fossilização, as partes fossilizadas podem ser removidas por erosão; d) daquilo que restar, só parte dos fósseis será achada e coletada.

6. ${ }^{\circ}$ Existem limitações de interpretação:

a) Alguns ambientes não têm registro geológico (é o caso do ambiente de costas rochosas, por exemplo); b) alguns organismos são fossilizados fora de seu ambiente de vida; c) apesar de todo o cuidado na interpretação, as deduções não podem ser comprovadas por que os organismos não podem ser ressuscitados; d) a abordagem uniformitária (atualística) pode falhar à medida que ambientes paleogeográficos podem faltar; e) o "habitat" (ou hábito) de vida dos organismos pode ter variado.

A Paleoecologia divide-se em Paleoautoecologia, 'na qual o estudo ecológico leva em consideração os organismos fósseis como indivíduos ou pequenos grupos taxonômicos, mas não como assembléias e Paleossinecologia, que é o estudo das comunidades viventes no passado, suas relações com seu ambiente físico e químico e as relações entre elas mesmas.

\section{DEDUÇÕES MORFOLÓGICAS}

A anatomia dos fósseis espelha dois aspectos importantes: a adaptação ambiental e a evolução. Esta é fenômeno irreversível e caracterizado pela transgressão de identidade a um nível selecionado de organização biótica. Sob o aspecto populacional a identidade é transgredida através da mutação, combinação genética e seleção natural. Já a adaptação ambiental não é transmitida geneticamente, a menos que se consubstancie em mutação genética. 
Rev. IG, São Paulo, 1(2):33-38, jul./dez. 1980

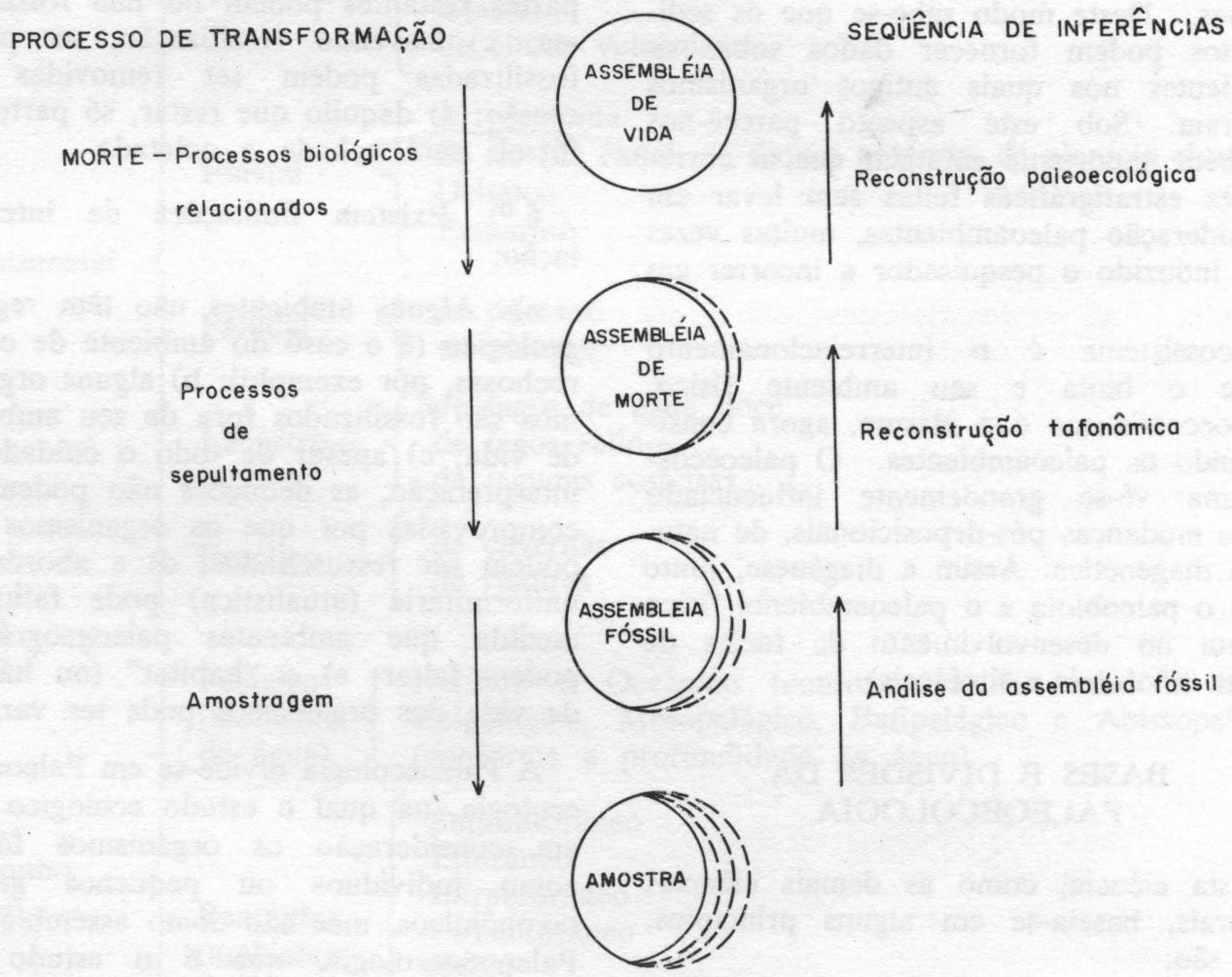

HISTÓRIA DA FOSSILIZAÇÃO 
Nós podemos fazer deduções acerca de paleoambientes com base no uniformitarismo, ou seja, podemos deduzir ambientes e modos de vida de fósseis pelo nosso conhecimento das formas de representantes viventes. Entretanto também é possível fazermos deduções baseadas somente na morfologia dos fósseis, ou seja, na sua anatomia, mesmo quando não existe possibilidade de comparação com organismos atualmente viventes. Nessa linha de pensamento, dois termos precisam ficar bem claros, a analogia, que é a similaridade morfológica sem origem comum e a homologia, que é a similaridade morfológica por origem comum (este é o caso de asas de morcegos e aves, que poderão ter-se derivado dos arcossauros).

Da anatomia, ou seja, dos restos fossilizados podem ser feitas deduções funcionais, é o campo da morfologia funcional. Em fósseis jamais se pode estudar a fisiologia, mas somente a anatomia, entretanto com base nesta pode-se deduzir aquilo que os antigos seres viventes "fizeram". Assim, do estudo adequado dos restos fossilizados podem-se obter importantes informações sobre função, hábito, "habitat" e até sobre doenças e acidentes que alguns indivíduos poderiam ter tido ou sofrido.

\section{HISTÓRIA DA FOSSILIZAÇÃO (HOLTZMAN, 1979)}

É a seguinte a seqüência dos principais processos de transformação e inferências correspondentes relacionando uma assembléia de vida a uma coleção fóssil.

Os processos de transformação envolvem grandes perdas e distorções de informações e por isso a reconstrução da assembléia de vida requer uma seqüência de inferências que conduz os processos de transformação em ordem inversa. Essa seqüência reconstrói paulatinamente a assembléia fóssil, a assembléia de morte e a de vida, removendo um por um os efeitos do3 processos de transformação.

Desse modo, quando se utiliza a anatomia do fóssil para reconstrução de seu ambiente de vida, várias precauções devem ser feitas e para isso as seguintes definições são úteis:
Fósseis identificáveis são os que podem ser colocados taxonomicamente em grupos conhecidos (usualmente espécies).

Elementos identificáveis ou simplesmenta elementos são as partes dos esqueletos dos organismos que podem ser identificadas.

Espécimem é o eonjunto dos restos que levam a um outrora indivíduo vivente (desde que esses restos contenham um ou mais elementos identificáveis).

Número de elementos por indivíduo é o número mínimo de elementos que podem ser preservados para um indivíduo. Ele depende em parte da experiência do paleontólogo, do estado de preservação dos fósseis e da morfológica similaridade de outras espécies da assembléia.

Preservação diferencial de elementos é a diferença de probabilidade de preservação dos vários elementos de uma espécie.

Número efetivo de elementos por indivíduo (de uma dada espécie) na amostra é a relação entre o conteúdo total de elementos dessa espécie e o conteúdo de elementos mais abundantemente preservados.

Grau de fragmentação é a relação entre o conteúdo total de elementos encontrados por indivíduo e o número efetivo de elementos por indivíduo. Assim sendo, esses dados podem ser extrapolados, obtendo-se o grau de fragmentação para grupos maiores que espécies.

\section{PROPOSIÇÕES}

1.a) A doutrina da sobrevivência do organismo mais adaptado é matéria ecológica, desde que os mais adaptados a sobreviver são os melhores adaptados em termos de hábito e "habitat". Infelizmente a grande maioria dos estudos evolucionários em Paleontologia tem sido feita em simples base de sucessão morfológica, desligada do estudo de ambientes contemporâneos e sucessivos.

2.a) A anatomia dos fósseis espelha seu fenotipo (que é decorrente do genotipo) e sua adaptação ambiental, sendo que esta não é transmitida geneticamente se não reflete a ação dos gens. $\mathrm{O}$ assunto, bem o sabemos, é polêmico e a respeito diz KRASSILOV (1978): "Existe entre os 
estratígrafos o dilema "ambiental versus evolucionário", ou seja: A pressão de seleção seria alterada por intermitentes mudanças no ambiente ou essas mudanças ambientais seriam insuficientes para alterar a pressão de seleção?".

3. ${ }^{\text {) }}$ As formas adaptativas não se perpetuam através dos descendentes, quando se trata de caracteres adquiridos, só sendo transmitidas as alterações anatômicas que são consequiência do arranjo genético (caso dos arcóides).

Existe um aparente antagonismo entre adaptação e especialização, já que os organismos com dificuldades de especialização, são forçados a se adaptarem aos ambientes e isso acaba por levá-los a viverem em nichos pouco explorados, o que lhes permite proliferar com facilidade. Por outro lado, os organismos que não encontram dificuldade de especialização tendem a evitar nichos com duras condições de vida.

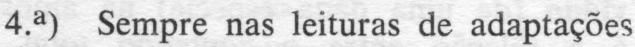
ecológicas nota-se que o tom dos autores é no sentido de que o organismo, por um processo racional, buscou deliberadamente modificar sua anatomia para levar vantagem na competição com outros grupos taxonômicos. Essa entretanto não pode ter sido a intenção de autor algum, já que sabe-se que no processo evolutivo a mutação dá-se ao acaso e mesmo a combinação genética entre seres irracionais não poderia ser guiada no intuito de melhoria racial. Quando se trata de caráter adquirido, também não se pode admitir intervenção racional.

Parece-nos razoável a crítica, pois que sempre a modificação no hábito ou na forma de fósseis é consequiência e não causa.

5. a) A resposta orgânica ao evento geológico demora algum tempo, que em muitos casos pode ser negligenciado.

A respeito diz KRASSILOV (1978): "Os eventos tectônicos e climáticos sentidos no mundo afetam os diferentes ecossistemas de modo similar e o sincronismo das respostas depende da velocidade relativa das mesmas. Os últimos amonites e dinossauros foram encontrados nos mesmos leitos da Formação Lance, o que mostra que as evidências de transtornos em ecossistemas marinhos e terrestres ocorreram próximas no tempo, entretanto esses transtornos podem ter ocorrido com maior espaço de tempo".

"Quanto mais nos afastamos no tempo geológico, a demora na resposta pode ir sendo negligenciada, de tal modo que o registro bioestratigráfico pode ser considerado como sincrônico com os eventos tectônicos e isso serve como base para a classificação estratigráfica".

\section{AGRADECIMENTOS}

O autor agradece ao Prof. Dr. Antônio Carlos Rocha Campos pelo material fornecido e útil ao presente estudo, bem como pela iniciação em tema tão importante.

\section{BIBLIOGRAFIA}

HOLTZMAN, R. C. - 1979 - Maximum likelihood estimation of fossil assemblage composition. Paleobiology, Chicago, 5(2):77-79.
KRASSILOV, V. - 1978 - Organic evolution and natural stratigraphical classification. Lethaia, Oslo, 11(2):93-104. 